\title{
Jejunal Perfusion of Simple and Conjugated Folates in Celiac Sprue
}

\author{
Charles H. Halsted, Ann M. Reisenauer, John J. Romero, David S. Cantor, \\ and BORIS RUEBNER \\ From the Department of Medicine, Johns Hopkins Hospital, Baltimore, Maryland 21205, and the \\ Departments of Internal Medicine and Pathology, Sacramento Medical Center-University \\ of California, Davis, California 95616
}

A B S TRACT The intestinal absorption of $\left[{ }^{3} \mathrm{H}\right]$ pteroylmonoglutamate (simple folic acid) and pteroyl$\mu\left[{ }^{14} \mathrm{C}\right]$ glutamyl- $\gamma$-hexaglutamate $\left(\left[{ }^{14} \mathrm{C}\right] \mathrm{PG}-7\right.$, conjugated folic acid) was assessed by the method of jejunal perfusion in five patients with proven celiac sprue who were studied after a gluten-containing or a gluten-free diet, and in nine normal subjects. The luminal disappearance of each folate was markedly impaired after exposure of the patients to dietary gluten and improved by gluten restriction, but not to within the range found in the normal subjects. In each experiment, column chromatography of the luminal aspirates revealed similar spectra of hydrolytic products of $\left[{ }^{14} \mathrm{C}\right] \mathrm{PG}-7$, whereas the fraction of the distal aspirate chromatogram appearing as pteroyl- $\mu\left[{ }^{14} \mathrm{C}\right]$ glutamyl- $\gamma$-monoglutamate $\left(\left[{ }^{14} \mathrm{C}\right]\right.$ PG-1) was similar in all three groups. By accounting for the variable effects of absorption on the luminal appearance of $\left[{ }^{14} \mathrm{C}\right] \mathrm{PG}-1$ and by correcting for mucosal hydrolysis which was not followed by release of $\left[{ }^{14} \mathrm{C}\right] \mathrm{PG}-1$ to the luminal contents, the calculated rate of in vivo hydrolysis of $\left[{ }^{14} \mathrm{C}\right] \mathrm{PG}-7$ to $\left[{ }^{14} \mathrm{C}\right] \mathrm{PG}-1$ was found impaired in both celiac sprue groups, with significant improvement on treatment. In mucosal biopsies from the sprue patients, the in vitro activity of folate conjugase in whole homogenates was higher and the activity of disaccharidase lower than in a group of 12 normal mucosal biopsies. These in vitro data suggest that the predominant cellular location of mucosal folate conjugase is different from that of disaccharidase, whereas comparison with the re-

This work was presented at meetings of the American Federation for Clinical Research at Carmel, Calif., February 1976, and Atlantic City, N. J., May 1976, and was reported in abstract form in 1976. Clin. Res. 24: 104A, 295A.

Address reprint requests to Dr. Halsted, TB 171, School of Medicine, University of California, Davis, Calif. 95616.

Received for publication 8 April 1976 and in revised form 24 January 1977. sults of in vivo hydrolysis suggests that measurement of the enzyme in whole mucosal homogenates overestimates its significant digestive activity. The present studies indicate that $(a)$ the mucosal lesion of celiac sprue significantly limits the intestinal absorption of both simple and conjugated folate, and $(b)$ malabsorption of conjugated folate results from a combination of impaired hydrolysis and decreased mucosal uptake of hydrolytic product.

\section{INTRODUCTION}

Naturally occurring folate exists primarily as pteroylmonoglutamate, or simple folate, conjugated in $\gamma$ peptide linkage with up to six additional glutamyl units (1). Studies using synthetic folates have shown that pteroylpolyglutamates are hydrolyzed to pteroylmonoglutamate during the process of intestinal absorption (2-4). The small intestinal mucosa is a potent source of the hydrolytic enzyme $(5,6)$, a $\gamma$-carboxypeptidase (7) referred to as folate conjugase. Thus, intestinal malabsorption of conjugated folate could result from decreased hydrolysis, decreased intestinal absorption of the hydrolytic product pteroylmonoglutamate, or a combination of these effects. These possibilities were studied by the jejunal perfusion method in five patients with proven celiac sprue and in nine healthy control subjects. The data were supplemented by direct measurements of jejunal mucosal folate conjugase, lactase, and sucrase in saline homogenates of biopsies from the patients and from a group of 12 normal biopsies.

\section{METHODS}

Three men and two women, ages 43-59 yr, gave a 2-20 yr history of diarrhea with weight loss or inability to gain weight. One patient, H. P., was studied at the Johns Hop- 
kins Hospital, Baltimore, Md., ${ }^{1}$ and the remaining four patients were studied at the University of California, Davis, and the Sacramento Medical Center, Sacramento, Calif. In each patient, the diagnosis of celiac sprue was indicated by the demonstration of intestinal malabsorption with a characteristic flat jejunal mucosal biopsy, features which improved with dietary gluten restriction, or which were made worse by gluten challenge. Diagnostic evaluation after each dietary regimen included measurement of levels of serum folate (8), the daily excretion of lipid in feces collected over a 3 -day period (9), and the excretion of $D$-xylose in the urine collected for $5 \mathrm{~h}$ after a $25-\mathrm{g}$ oral dose (10). Jejunal mucosal specimens were obtained with the Crosby capsule and graded for severity according to standard criteria, with $4^{+}$abnormality denoting a flat mucosa (11). A portion of each specimen was frozen in a dry ice-acetone bath for subsequent enzymatic analysis. Evaluation of intestinal absorption, intestinal biopsies, and jejunal folate perfusion studies were performed twice in each patient. Four patients were studied after initial evaluation while on a gluten-containing diet, and again in clinical and laboratory remission after a 6-wk period of gluten restriction. One patient was studied first in clinical remission and again after a 10-day dietary challenge of gluten (at least four slices of whole wheat bread per day). During the treatment periods, one patient received $20 \mathrm{mg} /$ day prednisone and two patients received $1 \mathrm{mg} /$ day oral folic acid (Table I). In addition, each patient received $15 \mathrm{mg}$ intramuscular folic acid on completion of each perfusion to minimize isotope retention. A control group of nine healthy adults was composed of five previously reported subjects (4) and four additional healthy volunteers; eight were male and one was female, ranging in age from 25 to 53 yr. All procedures were approved by the Committee on Human Investigations, Johns Hopkins Medical Institutions, or the Human Subjects Committee of the University of California, Davis, and required informed consent from each volunteer.

\section{Jejunal perfusion studies}

The jejunal perfusion solution and procedure were identical to those used in a previous study of normal subjects (4). The materials included $3^{\prime}, 5^{\prime}, 9^{\prime}\left[{ }^{3} \mathrm{H}\right]$ pteroylmonoglutamate (Amersham/Searle Corp., Arlington Heights, Ill.) and pteroyl- $\mu\left[{ }^{14} \mathrm{C}\right]$ glutamyl- $\gamma$-hexaglutamate. ${ }^{2}$ The latter compound was synthesized by the solid-phase method so that the ${ }^{14} \mathrm{C}$ label was on the first glutamyl unit (12), and was provided by The Nutrition Program, University of Alabama. As described (4), these folates were purified on DEAEcellulose columns and were quantitated spectrophotometrically using peak absorbance at 256,285 , and $365 \mathrm{~nm}$. The infusion solution was $1,000 \mathrm{ml}$ isotonic saline, adjusted to $\mathrm{pH} 7.0$ before use, containing the nonabsorbable marker polyethylene glycol, 8 g/liter, and each purified folate in a concentration of $2 \mu \mathrm{M}$ with specific activities of approximately $1,800,000 \mathrm{cpm} / \mu \mathrm{mol}$. Henceforth, these folates will be referred to as $\left[{ }^{3} \mathrm{H}\right] \mathrm{PG}-1^{2}\left(\left[{ }^{3} \mathrm{H}\right]\right.$ pteroylmono-

\footnotetext{
${ }^{1}$ An association of celiac sprue with Fabry's disease in this patient was reported in 1975. Ann. Intern. Med. 83: 524.

${ }^{2}$ Abbreviations used in this paper: [ $\left.{ }^{14} \mathrm{C}\right] \mathrm{PG}-1$, pteroyl$\mu\left[{ }^{[4} \mathrm{C}\right]$ glutamyl- $\gamma$-monoglutamate; [ $\left.{ }^{14} \mathrm{C}\right] \mathrm{PG}-7$, pteroyl- $\mu\left[{ }^{14} \mathrm{C}\right]-$ glutamyl- $\gamma$-hexaglutamate; $f$, fraction; $G$, gluten-containing diet; GF, gluten-free diet; $\left[{ }^{3} \mathbf{H}\right]$ PG-1, $\left[{ }^{3} \mathbf{H}\right]$ pteroylmonoglutamate; LD, luminal disappearances; PG-1, pteroylmonoglutamate; $R$, recovery.
}

glutamate) and $\left[{ }^{14} \mathrm{C}\right] \mathrm{PG}-7$ (pteroyl- $\mu\left[{ }^{14} \mathrm{C}\right]$ glutamyl- $\gamma$-hexaglutamate).

The solution was infused at $10 \mathrm{ml} / \mathrm{min}$ at a site $10 \mathrm{~cm}$ distal to the ligament of Treitz and, after a 50-min equilibration period, samples were collected and pooled from ports 15 and $30 \mathrm{~cm}$ downstream at rates of $1 \mathrm{ml} / \mathrm{min}$. Aliquots of each aspirate pool were removed for measurements of polyethylene glycol (13) and for radioisotope counting on a Beckman-LS230 liquid scintillation counter (Beckman Instruments, Fullerton, Calif.) set for double-label counting, using a commercial scintillant (Scintisol, Isolab, Inc., Akron, Ohio). The remainder of each aspirate pool was acidified to $\mathrm{pH} 2.8$ with $10 \%$ trichloroacetic acid to inactivate enzymes and was stored at $-70^{\circ} \mathrm{C}$. The pools were subsequently thawed, neutralized, and subjected to column chromatography to detect oxidized products of hydrolysis of $\left[{ }^{14} \mathrm{C}\right] \mathrm{PG}-7$. These procedures do not alter the specific activities of the folates employed in these studies (4). The chromatographic procedures, employing DEAEcellulose, a linear sodium chloride gradient, and spectrally pure nonradioactive pteroylglutamate markers, were exactly as described previously (4). These methods have proven effective in separating oxidized pteroylglutamates (14), which are spectrally distinct from reduced and substituted folates (15). These chromatographic techniques permitted greater than $90 \%$ recovery of $\left[{ }^{14} \mathrm{C}\right]$ pteroylglutamates, which were entirely in the oxidized spectrum.

\section{In vitro studies}

To determine the possible presence of unbound folate conjugase within the luminal contents, $\left[{ }^{14} \mathrm{C}\right] \mathrm{PG}-7$ was exposed in vitro to intestinal juice under physical conditions similar to those employed in the perfusion studies. The initial perfusion of patient $D$. R. was preceded by a $60-\mathrm{min}$ perfusion with isotonic saline. $25 \mathrm{ml}$ of the pooled aspirates from the saline perfusion was incubated with $\left[{ }^{14} \mathrm{C}\right] \mathrm{PG}-7$ in a $2-\mu \mathrm{M}$ concentration for $15 \mathrm{~min}$ at $37^{\circ} \mathrm{C}$ at (intraluminal) pH 5.0, after which $10 \%$ trichloroacetic acid was added to bring the $\mathrm{pH}$ to 2.8 , and the reactant mixture was then subjected to column chromatography to detect reactant products.

Jejunal mucosa obtained by biopsy from patient $D$. $R$. before treatment was homogenized in $2 \mathrm{ml}$ of cold saline using a glass homogenizer. $1 \mathrm{ml}$ of whole homogenate, containing $1.09 \mathrm{mg}$ protein (16), was incubated in $0.1 \mathrm{M}$ sodium acetate buffer, $\mathrm{pH} 4.5$, with $20 \mathrm{nmol}\left[{ }^{14} \mathrm{C}\right] \mathrm{PG}-7$ in a $2.0-\mathrm{ml}$ volume for $15 \mathrm{~min}$ at $37^{\circ} \mathrm{C}$. The reaction was stopped by the addition of $0.5 \mathrm{ml}$ of $10 \%$ trichloroacetic acid and, after centrifugation, the supernate was subjected to the column-chromatographic procedure described above. A similar procedure was followed using a whole saline homogenate of normal jejunal mucosa which contained $2.38 \mathrm{mg}$ protein $/ \mathrm{ml}$. The fraction of each chromatogram represented by pteroyl- $\mu\left[{ }^{14} \mathrm{C}\right]$ glutamyl- $\gamma$-monoglutamate $\left(\left[{ }^{14} \mathrm{C}\right] \mathrm{PG}-1\right)$ was determined by weight. Hydrolysis of $\left[{ }^{14} \mathrm{C}\right]-$ PG-7 to $\left[{ }^{14} \mathrm{C}\right] \mathrm{PG}-1$ was calculated as $\mathrm{nmol} / \mathrm{mg}$ protein per 15 min.

The charcoal precipitation method of Krumdieck and Baugh (17) was used to measure jejunal mucosal folate conjugase in whole saline homogenates of biopsy specimens which were obtained from the patients after each dietary regimen and in a group of 12 histologically normal biopsies. The substrate was pure pteroyldi- $\gamma$-glutamyl[ $\left[{ }^{14} \mathrm{C}\right]$ glutamic acid, synthesized by the solid-phase method (12), and provided by The Nutrition Program, University of Alabama. This assay measures the rate of cleavage of the peptide link between the second and third glutamyl units. After a 
preliminary kinetic study, a substrate concentration of 20 nmol/1.5-ml reaction tube was chosen. Assays were performed at $\mathrm{pH}$ of 4.5 at $37^{\circ} \mathrm{C}$ and for a 15 -min incubation time. In each specimen, mucosal lactase and sucrase were measured by the method of Dahlqvist (18), and mucosal protein by the method of Lowry (16). Folate conjugase activity was expressed as nanomoles/milligram protein per $15 \mathrm{~min}$, and lactase and sucrase activities were expressed as units/gram protein per hour.

\section{Calculations}

Previously described formulas (4) were used to calculate luminal disappearances (LD), which were expressed as a percent of each folate perfused over the $30-\mathrm{cm}$ jejunal segment. Net water flux was calculated for the distal 15 $\mathrm{cm}$ of each segment (19).

In vivo hydrolysis of $\left[{ }^{14} \mathrm{C}\right] \mathrm{PG}-7$ to $\left[{ }^{14} \mathrm{C}\right] \mathrm{PG}-1$ over the $30-$ cm segment was calculated by two formulas. "Observed hydrolysis" was calculated as that which is followed by release of end product $\left[{ }^{14} \mathrm{C}\right] \mathrm{PG}-1$ to the luminal contents before its absorption. This formula, accounting for the effect of varied absorption on the luminal accumulation of $\left[{ }^{14} \mathrm{C}\right]$ PG-1, assumes that $\left[{ }^{14} \mathrm{C}\right] \mathrm{PG}-1$ is absorbed by the same transport process as $\left[{ }^{3} \mathrm{H}\right] \mathrm{PG}-1$. Assuming that the intestinal absorption of $\left[{ }^{14} \mathrm{C}\right] \mathrm{PG}-7$ requires its complete degradation to [14C]PG-1 (3), "corrected hydrolysis" was calculated by a formula which would account both for the $\left[{ }^{14} \mathrm{C}\right] \mathrm{PG}-1$ which is released to the lumen and that which is absorbed directly from the mucosal site of hydrolysis without detection in the luminal contents. The previous evidence that pteroylpolyglutamate is hydrolyzed in vivo to pteroylmonoglutamate (PG-1) during intestinal absorption, and that PG-1 derived from mucosal hydrolysis of pteroylpolyglutamate uses the same transport system as free PG-1 has been recently and extensively reviewed (20). Our cumulative evidence for the sequence of pteroylpolyglutamate hydrolysis and absorption is considered in the discussion.

Observed hydrolysis. The recovery of $\left[{ }^{14} \mathrm{C}\right] \mathrm{PG}-1$ in the $30-\mathrm{cm}$ intestinal aspirate, $\left(\mathrm{R}\left[{ }^{14} \mathrm{C}\right] \mathrm{PG}-1\right)$, was calculated as the product of the percent of unabsorbed $\left[{ }^{14} \mathrm{C}\right]$ folate and the fraction (f) by weight of the $30-\mathrm{cm}$ aspirate chromatogram represented by $\left[{ }^{14} \mathrm{C}\right] \mathrm{PG}-1$. Thus, $R\left[{ }^{14} \mathrm{C}\right] \mathrm{PG}-1=(100$ $\left.{ }^{L D}{ }^{14} \mathrm{C}\right) \cdot f$. The recovery $(R)$ of unabsorbed $\left[{ }^{3} \mathrm{H}\right] \mathrm{PG}-1$ in the $30-\mathrm{cm}$ aspirate is expressed as: $R\left[{ }^{3} \mathrm{H}\right] \mathrm{PG}-1=100-\mathrm{LD}^{3} \mathrm{H}$. If there were no absorption of PG-1, its recovery at $30 \mathrm{~cm}$ would be $100 \%$, or the reciprocal of $R\left[{ }^{3} \mathrm{H}\right] \mathrm{PG}-1$. Assuming that luminal $\left[{ }^{14} \mathrm{C}\right] \mathrm{PG}-1$ is absorbed by the same mechanism as free $\left[{ }^{3} \mathrm{H}\right] \mathrm{PG}-1$, if there were no absorption of $\left[{ }^{14} \mathrm{C}\right] \mathrm{PG}-1$ its expected recovery at $30 \mathrm{~cm}$ would be equal to the product of $R\left[{ }^{14} \mathrm{C}\right] P G-1$ and the reciprocal of $R\left[{ }^{3} \mathrm{H}\right] P G-1$. Combining, the observed mucosal hydrolysis of $\left[{ }^{14} \mathrm{C}\right] \mathrm{PG}-7$ which is followed by release of $\left[{ }^{14} \mathrm{C}\right] \mathrm{PG}-1$ to the luminal

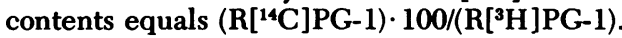

Corrected hydrolysis. Corrected hydrolysis was expressed as the sum of the $L D$ of $\left[{ }^{14} \mathrm{C}\right] \mathrm{PG}-7$ and the $\left[{ }^{14} \mathrm{C}\right]-$ folate remaining as $\left[{ }^{14} \mathrm{C}\right] P G-1$ at the distal $30-\mathrm{cm}$ aspiration port, or: $L D\left[{ }^{14} \mathrm{C}\right] \mathrm{PG}-7+\mathrm{R}\left[{ }^{14} \mathrm{C}\right] \mathrm{PG}-1$.

The relationship between these two formulas can be tested by using each to calculate unmeasured hydrolysis, or the percent of perfused $\left[{ }^{14} \mathrm{C}\right] \mathrm{PG}-7$ hydrolyzed and absorbed without luminal detection of $\left[{ }^{14} \mathrm{C}\right] \mathrm{PG}-1$. On the one hand, if complete hydrolysis were described by the calculation for observed hydrolysis, then the LD of $\left[{ }^{14} \mathrm{C}\right] \mathrm{PG}-7$ would be equal to the LD of $\left[{ }^{14} \mathrm{C}\right] \mathrm{PG}-1$ after its release to the lumen. LD $\left[{ }^{14} \mathrm{C}\right]$ PG-1 can be calculated as the product of observed hydrolysis and $L D\left[{ }^{3} \mathrm{H}\right] \mathrm{PG}-1$, divided by 100 . The differ-
TABLE I

Clinical and Laboratory Features of the Patients

\begin{tabular}{|c|c|c|c|c|c|c|c|c|}
\hline Patient* & Age & Sex & Diet! & Hgb & $\begin{array}{l}\text { Serum } \\
\text { folate }\end{array}$ & $\begin{array}{l}\text { Urine } \\
\text { xylose }\end{array}$ & $\begin{array}{c}\text { Fecal } \\
\text { fat }\end{array}$ & $\begin{array}{c}\text { Jejunal } \\
\text { morphology }\end{array}$ \\
\hline & \multicolumn{2}{|c|}{$y r$} & & $\mathrm{~g} / 100 \mathrm{mg}$ & $n g / m l$ & $g / 5 h$ & g/day & \\
\hline \multicolumn{3}{|l|}{ Normal } & & $12-16$ & $5-21$ & $>4.5$ & $<6.0$ & 0 \\
\hline \multirow[t]{2}{*}{ H. P. } & \multirow[t]{2}{*}{59} & \multirow[t]{2}{*}{$\mathbf{M}$} & G & 12.5 & 1.7 & 2.3 & 29.4 & $4+$ \\
\hline & & & GF & 13.9 & 18.0 & 4.9 & 1.4 & $2+$ \\
\hline \multirow[t]{2}{*}{ R. M. } & \multirow[t]{2}{*}{43} & \multirow[t]{2}{*}{$\mathbf{M}$} & G & 12.1 & 1.5 & 3.5 & 29.0 & $4+$ \\
\hline & & & GF & 14.2 & 8.0 & 5.6 & 8.9 & $2+$ \\
\hline \multirow[t]{2}{*}{ D. R. } & \multirow[t]{2}{*}{44} & \multirow[t]{2}{*}{$\mathbf{F}$} & G & 10.3 & 4.1 & 1.8 & 25.3 & $4+$ \\
\hline & & & GF & 12.6 & 15.0 & 4.3 & 17.5 & $2+$ \\
\hline \multirow[t]{2}{*}{ J. M. } & \multirow[t]{2}{*}{58} & \multirow[t]{2}{*}{$\mathbf{M}$} & G & 14.8 & 6.0 & 5.0 & 21.0 & $4+$ \\
\hline & & & GF & 15.1 & 8.0 & 7.0 & 14.0 & $3+$ \\
\hline \multirow[t]{2}{*}{ M. N. } & \multirow[t]{2}{*}{43} & \multirow[t]{2}{*}{$\mathbf{F}$} & GF & 13.0 & 3.8 & 3.3 & 8.4 & $2+$ \\
\hline & & & $G \S$ & 12.6 & 3.0 & 1.9 & 48.0 & $4+$ \\
\hline
\end{tabular}

* Folic acid, $1 \mathrm{mg} /$ day, orally administered between tests to H. P. and D. R. Prednisone, $20 \mathrm{mg} /$ day, administered between tests to D. R.

† G, gluten; GF, gluten-free.

$\$ 10$-day dietary gluten challenge.

ence between $\mathrm{LD}\left[{ }^{14} \mathrm{C}\right] \mathrm{PG}-7$ and calculated $\mathrm{LD}\left[{ }^{14} \mathrm{C}\right] \mathrm{PG}-1$ then becomes the percent of $\left[{ }^{14} \mathrm{C}\right] \mathrm{PG}-7$ which disappears after unmeasured hydrolysis. On the other hand, from the given definitions, unmeasured hydrolysis is the difference between corrected hydrolysis and observed hydrolysis. Applied to the results, identical values for unmeasured hydrolysis can be obtained by either method.

The paired $t$ test was used to compare results obtained after the two dietary regimens in the sprue groups, and the unpaired $t$ test was used to compare results with the normal subjects.

\section{RESULTS}

Clinical features. Table I documents the clinical features and diagnosis of celiac sprue by jejunal morphology, intestinal malabsorption, and response to treatment or to dietary gluten challenge.

Jejunal perfusion studies. Net secretion of water into the perfused lumen was observed in 9 of the 10 studies of the sprue patients (Table II). The rate of net water secretion was not significantly different in studies performed after dietary gluten (G) or in clinical remission (gluten-free diet, GF) and contrasted with net water absorption in the control group ( $P$ $<0.001)$. The mean LD of $\left[{ }^{3} \mathrm{H}\right] \mathrm{PG}-1$ and of $\left[{ }^{14} \mathrm{C}\right] \mathrm{PG}-7$ was significantly less in studies performed in $G$ than in GF $(P<0.02,<0.01$; paired $t$ test). Dietary gluten challenge in patient $M$. N. resulted in marked suppression of LD of each folate. In the group of patients, the LD of $\left[{ }^{3} \mathrm{H}\right] \mathrm{PG}-1$ was significantly greater than that of $\left[{ }^{14} \mathrm{C}\right] \mathrm{PG}-7$ after either dietary regimen $(P<0.02,<0.02$; paired $t$ test). A similar relationship 
TABLE II

Jejunal Perfusion Studies

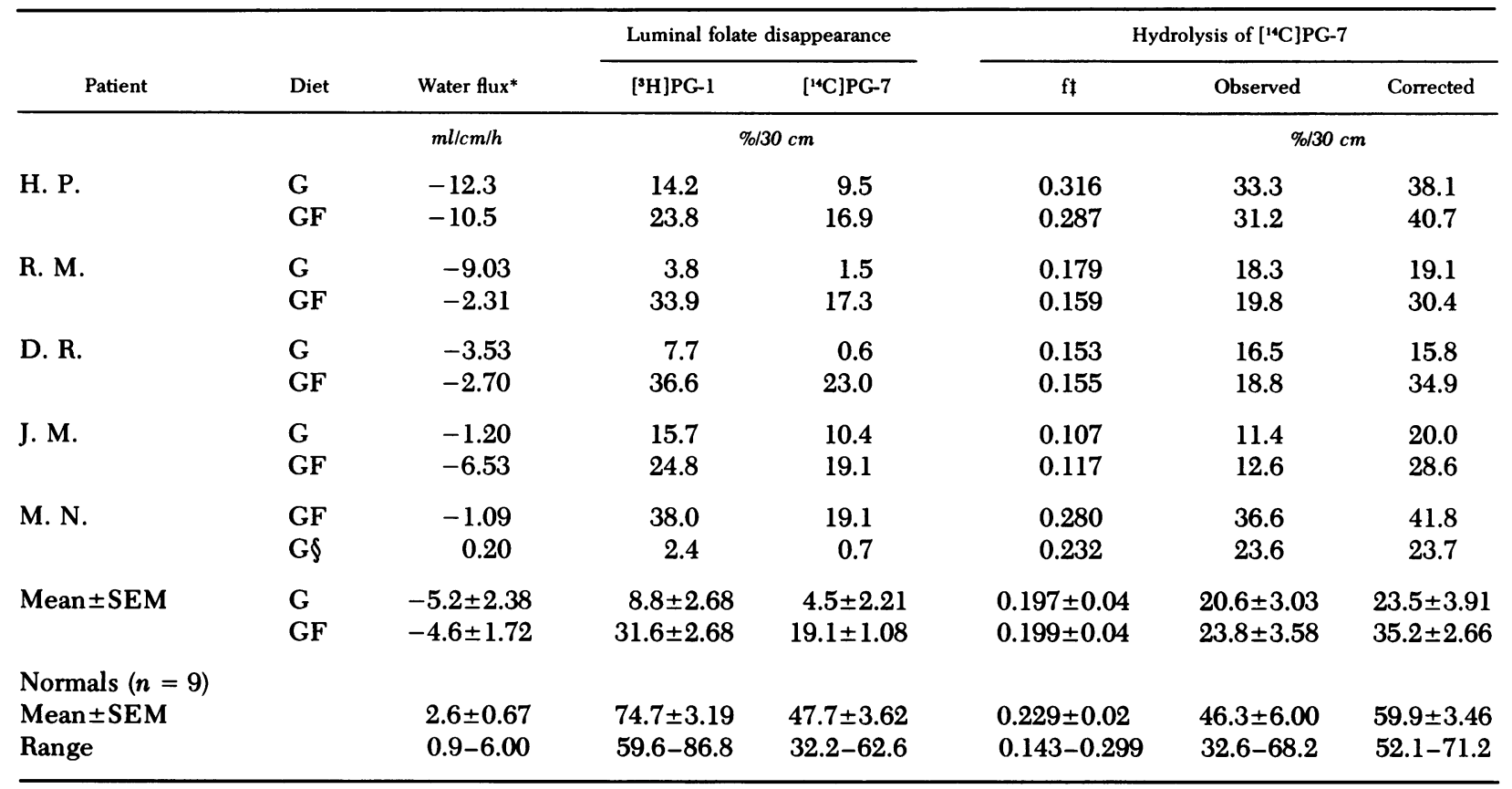

$*-$, Net secretion.

\$ Fraction of $30-\mathrm{cm}$ aspirate chromatogram appearing as $\left[{ }^{14} \mathrm{C}\right] \mathrm{PG}-1$.

$\S 10$-day dietary gluten challenge.

was observed in the control group $(P<0.001)$. Although the differences were not significant, the ratio of the mean LD of $\left[{ }^{3} \mathrm{H}\right] \mathrm{PG}-1$ to $\left[{ }^{14} \mathrm{C}\right] \mathrm{PG}-7$ was greater in $G$ (1.95) than in GF (1.65) and the control group (1.56). This ratio exceeded 2.5 in three patients (R. M., D. R., and M. N.) in group G (Table II). The values obtained for LD of each folate in clinical remission, GF, were significantly less than those found in the control group $(P<0.001,<0.001)$.

Column chromatography of each $15-$ and $30-\mathrm{cm}$ aspirate pool revealed seven ${ }^{14} \mathrm{C}$-labeled peaks. Similar patterns were obtained after each dietary regimen (Fig. 1) and the fraction of the chromatogram of each $30-\mathrm{cm}$ aspirate appearing as $\left[{ }^{14} \mathrm{C}\right] \mathrm{PG}-1$ was similar in all three groups (Table II). However, the calculated observed hydrolysis of $\left[{ }^{14} \mathrm{C}\right] \mathrm{PG}-7$, based on the recovery of luminal $\left[{ }^{14} \mathrm{C}\right] \mathrm{PG}-1$, was significantly less in the sprue groups, $20.6 \%(\mathrm{G})$ and $23.8 \%$ (GF), than in the control group, $46.3 \%(P<0.01,<0.01)$. The differences in corrected hydrolysis were more significant among the groups; $23.5 \%$ (G) vs. $35.2 \%$ (GF) ( $P$ $<0.02$, paired $t$ test) vs. $59.9 \%$ (control) $(P<0.001$, $<0.001$ ) (Table II).

In vitro studies. Incubation of $\left[{ }^{14} \mathrm{C}\right] \mathrm{PG}-7$ with intestinal aspirate obtained on saline perfusion of patient D. R. yielded no detectable degradation products (Fig. 2). After incubation of $\left[{ }^{14} \mathrm{C}\right] \mathrm{PG}-7$ with a whole saline homogenate of jejunal mucosa obtained from patient D. R. and from a normal subject, column chromatography revealed seven peaks of ${ }^{14} \mathrm{C}$-labeled pteroylglutamates (Fig. 3). Accounting for differences in protein concentration in the mucosal homogenates, the calculated rate of hydrolysis of $\left[{ }^{14} \mathrm{C}\right] \mathrm{PG}-7$ to $\left[{ }^{14} \mathrm{C}\right] \mathrm{PG}-1$ was $3.30 \mathrm{nmol} / \mathrm{mg}$ protein per $15 \mathrm{~min}$ in the sprue biopsy and $1.69 \mathrm{nmol} / \mathrm{mg}$ protein per 15 min in the normal biopsy. Using pteroyldi- $\gamma$-glutamyl$\left[{ }^{14} \mathrm{C}\right]$ glutamate as substrate, jejunal folate conjugase activity in biopsies obtained after gluten exposure was not significantly different from the activity in biopsies obtained after gluten-restricted diet and clinical remission (Fig. 4). In 12 normal biopsies, the activity of folate conjugase ranged from 2.6 to $6.5 \mathrm{nmol} / \mathrm{mg}$ protein per $15 \mathrm{~min}$ with a mean of 4.2 \pm 0.31 , significantly less than either sprue group. However, the activities of lactase and sucrase were significantly greater in the control group than in the sprue patients (Fig. 4).

\section{DISCUSSION}

Folate deficiency is a frequent cause of anemia in untreated celiac sprue (21). Previous studies in celiac sprue using oral doses of folate and measurements of serum levels and urinary excretion described folic 


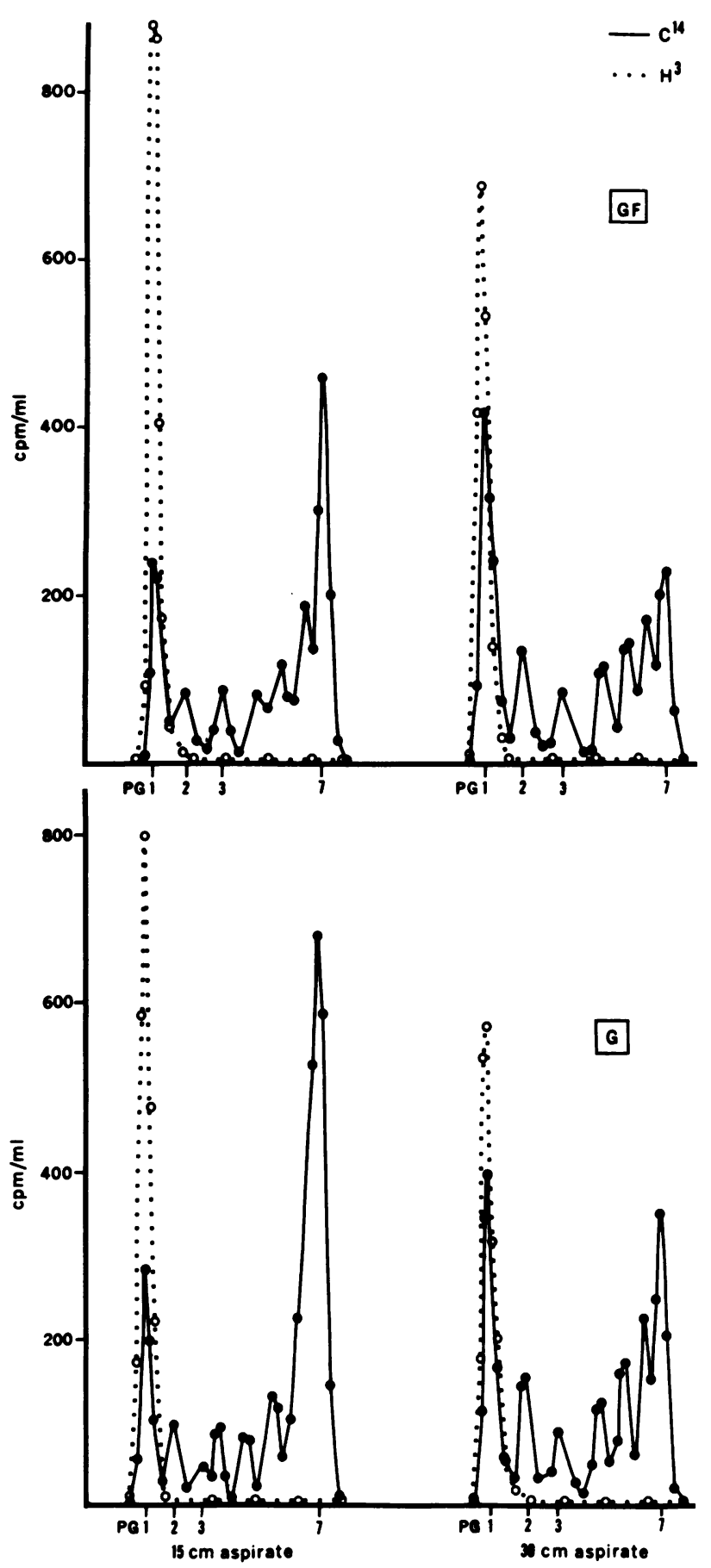

FIgURE 1 Chromatograms of intestinal aspirates obtained at 15 - and $30-\mathrm{cm}$ ports during perfusion of patient M. N., initially on gluten-free (GF, top) diet and after 10days challenge with dietary gluten ( $G$, bottom). The infusate contained equimolar $(2 \mu \mathrm{M})$ concentrations of $\left[{ }^{3} \mathrm{H}\right] \mathrm{PG}-1$ and $\left[{ }^{14} \mathrm{C}\right] \mathrm{PG}-7$. Unlabeled markers added to the aspirates and identified spectrophotometrically at $285 \mathrm{~nm}$ indicate peaks of PG-1 and certain pteroylpolyglutamates. After each dietary regimen, progressive hydrolysis of $\left.{ }^{[14} \mathrm{C}\right] \mathrm{PG}-7$ occurred between 15 and $30 \mathrm{~cm}$ as indicated by a simultaneous decrease in [ $\left.{ }^{14} \mathrm{C}\right] \mathrm{PG}-7$ and increase in $\left[{ }^{14} \mathrm{C}\right] \mathrm{PG}-1$.

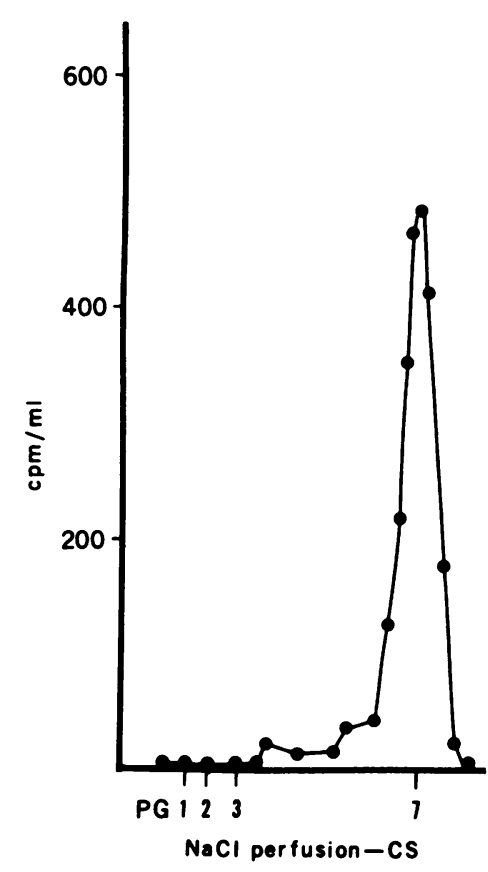

FIgURE 2 Chromatogram of incubated mixture (15 min, $\left.37^{\circ} \mathrm{C}\right)$ of $\left[{ }^{14} \mathrm{C}\right] \mathrm{PG}-7,2 \mu \mathrm{M}$, with intestinal aspirate, $\mathrm{pH} 5.0$, obtained after isotonic saline perfusion of patient $D$. R. before treatment. No degradation products were observed, indicating the absence of free intraluminal folate conjugase.

acid malabsorption in more than $88 \%$ of patients $(22,23)$, and equally poor absorption of PG-1 and yeast-derived conjugated folate (24). The present perfusion technique provides several distinct advantages over oral tolerance methods of measuring folate absorption. Interpretation of the data is not affected by variations in hepatic folate metabolism or renal excretion. The simultaneous administration of separately labeled $\left[{ }^{3} \mathrm{H}\right] \mathrm{PG}-1$ and $\left[{ }^{14} \mathrm{C}\right] \mathrm{PG}-7$ permits accurate analysis of differences in absorption rates of the two folates by avoiding variations which may occur when each compound is administered separately on different occasions.

LD of folates. The present studies clearly show that the jejunal LD of both $\left[{ }^{3} \mathrm{H}\right] P G-1$ and $\left[{ }^{14} \mathrm{C}\right] P G-7$ is markedly decreased in celiac sprue. As indicated by changes after treatment or gluten challenge, the impairment of luminal folate disappearance was related to the functional and histological severity of the mucosal lesion (Tables I and II). The data also suggest that patients with celiac sprue in early clinical remission are at continued risk for folate malabsorption and deficiency. The finding of net water secretion into the jejunum is consistent with observations of others who perfused the small intestine in untreated $(25,26)$ and in treated celiac sprue (26). Previous studies have shown parallel enhancement of water and folic acid absorption by glucose in normal 


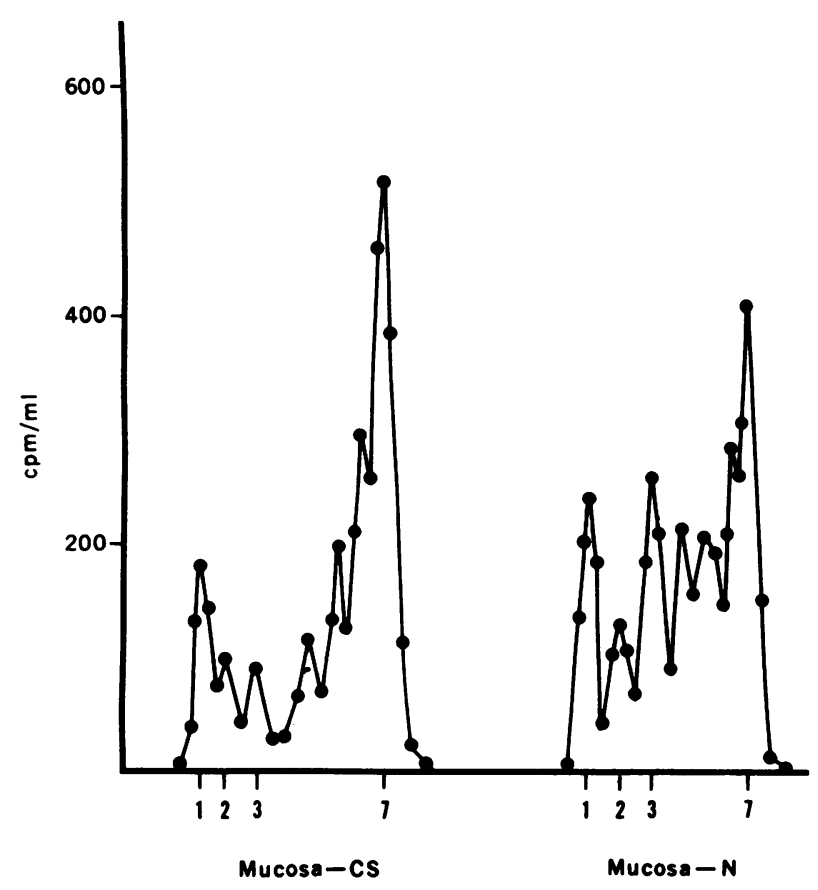

FIGURE 3 Chromatograms of mixture resulting from incubation ( $\left.15 \mathrm{~min}, 37^{\circ} \mathrm{C}, \mathrm{pH} 4.5\right)$ of $\left[{ }^{14} \mathrm{C}\right] \mathrm{PG}-7$ with a saline homogenate of jejunal mucosa obtained from patient $D$. R. before treatment (CS) and from a normal subject (N). Unlabeled markers were identified spectrophotometrically at $285 \mathrm{~nm}$. Folate degradation is demonstrated in each incubation by the production of a spectrum of ${ }^{14} \mathrm{C}$-labeled pteroylglutamates. The calculated conversion of $\left[{ }^{14} \mathrm{C}\right] \mathrm{PG}-7$ to $\left[{ }^{14} \mathrm{C}\right] \mathrm{PG}-1$ was $3.30 \mathrm{nmol} / \mathrm{mg}$ protein per $15 \mathrm{~min}$ in the sprue biopsy and $1.69 \mathrm{nmol} / \mathrm{mg}$ protein per $15 \mathrm{~min}$ in the normal biopsy.

subjects (27), whereas in celiac sprue, glucose fails to stimulate water $(25,26)$ or folic acid $(28)$ uptake by the perfused jejunum. The present data in celiac sprue imply that the jejunal uptake of folate from a saline solution is independent of net water flux, since the increase in uptake after gluten restriction was not paralleled by a similar change in net water flux. Similar observations were made in patients with tropical sprue (29).

Hydrolysis of $\left[{ }^{14} \mathrm{C}\right] P G-7$. The following observations from our laboratory. constitute reasonable evidence that perfused $\left[{ }^{14} \mathrm{C}\right] \mathrm{PG}-7$ is hydrolyzed by the jejunal mucosa, permitting partial recovery of its hydrolytic products in the luminal contents, and that the mucosal hydrolysis of $\left[{ }^{14} \mathrm{C}\right] \mathrm{PG}-7$ limits the intestinal absorption of its end product, $\left[{ }^{14} \mathrm{C}\right] \mathrm{PG}-1$. (a) We have consistently found in normal subjects (4), in tropical sprue (29), and now in celiac sprue that hydrolytic products of $\left[{ }^{14} \mathrm{C}\right] \mathrm{PG}-7$ appear intraluminally during its perfusion. In each of the three studies, progressive hydrolysis of $\left[{ }^{14} \mathrm{C}\right] \mathrm{PG}-7$ was suggested by the simultaneous decrease in $\left[{ }^{14} \mathrm{C}\right] \mathrm{PG}-7$ and increase in $\left[{ }^{14} \mathrm{C}\right] \mathrm{PG}-1$ in chromatograms of the
15- and 30-cm luminal aspirates (Fig. 1). (b) Although there are no data to bear on the process of hydrolysis of $\left[{ }^{14} \mathrm{C}\right] \mathrm{PG}-7$ in the fed state, in each study we have shown that the patterns of hydrolysis obtained during perfusion of $\left[{ }^{14} \mathrm{C}\right] \mathrm{PG}-7$ in the fasting subject cannot be reproduced by in vitro incubation of intraluminal contents with $\left[{ }^{14} \mathrm{C}\right] \mathrm{PG}-7$ (Fig. 2). These data, supported by the findings presented in Fig. 3, imply that hydrolysis of perfused $\left[{ }^{14} \mathrm{C}\right] \mathrm{PG}-7$ requires its contact with the intestinal mucosa and are consistent with previous evidence $(5,6)$ that the intestinal mucosa is the site of hydrolysis of conjugated folate. (c) A limiting effect of hydrolysis on absorption of $\left[{ }^{14} \mathrm{C}\right]-$ PG-7 was suggested in each study by the finding that the LD of $\left[{ }^{3} \mathrm{H}\right] \mathrm{PG}-1$ consistently and significantly exceeded that of $\left[{ }^{14} \mathrm{C}\right] \mathrm{PG}-7$. In the present study, a greater than normal limitation of hydrolysis on the absorption of $\left[{ }^{14} \mathrm{C}\right] \mathrm{PG}-7$ in celiac sprue was suggested by the observation that the ratio of the mean LD of $\left[{ }^{3} \mathrm{H}\right] \mathrm{PG}-1$ and $\left[{ }^{14} \mathrm{C}\right] \mathrm{PG}-7$ was greater in untreated celiac sprue than in the treated sprue and control group.

Analysis of the chromatographic data by two separate formulas indicates that the in vivo hydrolysis of perfused $\left[{ }^{14} \mathrm{C}\right] \mathrm{PG}-7$ was significantly impaired in both sprue groups. On the one hand, the $\left[{ }^{14} \mathrm{C}\right]$ folate chromatograms of the intestinal aspirates were similar after each diet (Fig. 1) and similar to those obtained from normal subjects (4), whereas the fraction of each 30$\mathrm{cm}$ aspirate appearing as $\left[{ }^{14} \mathrm{C}\right] \mathrm{PG}-1$ was similar in each group (Table II). However, accumulation of $\left[{ }^{14} \mathrm{C}\right] \mathrm{PG}-1$ within the lumen is the combined result of its production by hydrolysis and its disappearance by absorption. The observed hydrolysis of $\left[{ }^{14} \mathrm{C}\right] \mathrm{PG}-7$ was calculated by a formula which describes the production of $\left[{ }^{14} \mathrm{C}\right] \mathrm{PG}-1$ in the mucosa and its release to the lumen, using the LD rate of $\left[{ }^{3} \mathrm{H}\right] \mathrm{PG}-1$ to correct for the effect of varied absorption of the luminal recovery of $\left[{ }^{14} \mathrm{C}\right] \mathrm{PG}-1$. As shown in Table II, ob-

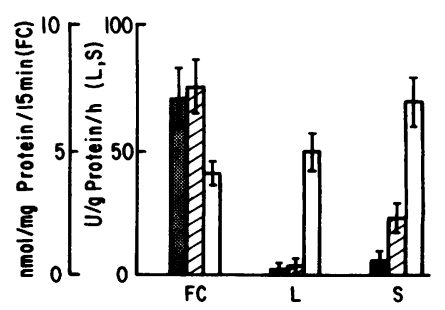

FIGURE 4 Activities of folate conjugase (FC), lactase (L), and sucrase $(S)$ in biopsies obtained in celiac sprue patients after gluten-containing diet (shaded bars, $n=5$ ), and gluten-free diet (hatched bars, $n=5$ ), and from histologically normal biopsies (open bars, $n=12$ ). The activity of FC was significantly greater than normal in the sprue biopsies $(P<0.01,<0.01)$ whereas activities of $L$ and $S$ were significantly less than normal in the sprue biopsies $(P<0.001$, $<0.001)$. 
served hydrolysis was significantly less in both sprue groups than the control group. By making the further assumption that the absorption of $\left[{ }^{14} \mathrm{C}\right] \mathrm{PG}-7$ requires its complete mucosal hydrolysis to $\left[{ }^{14} \mathrm{C}\right] \mathrm{PG}-1$, a corrected hydrolytic rate was calculated which accounts both for end product $\left[{ }^{14} \mathrm{C}\right] \mathrm{PG}-1$ released to the lumen before absorption and that which is absorbed directly from the mucosal site of hydrolysis to the portal circulation. Using this formula, the corrected rate of hydrolysis exceeded the LD of $\left[{ }^{14} \mathrm{C}\right] \mathrm{PG}-7$ in every study. Furthermore, these data show a significant improvement in hydrolysis with treatment of celiac sprue, though the results in the treated group remained significantly less than normal. The data also show that in untreated celiac sprue the hydrolysis of $\left[{ }^{14} \mathrm{C}\right] \mathrm{PG}-7$ (about one-half the control value) was not as limited as its LD (1/10th the control value).

Jejunal mucosal folate conjugase. The present data confirm the findings of others $(30,31)$ that the in vitro activity of jejunal mucosal folate conjugase is increased in celiac sprue. The variance between these results and the calculated effect of celiac sprue on the in vivo hydrolysis of $\left[{ }^{14} \mathrm{C}\right] \mathrm{PG}-7$ suggests that the significant digestive activity of this enzyme is overestimated by its measurement in whole mucosal homogenates. In vitro measurement of mucosal folate conjugase does not define its activity in the mass of the jejunal absorbing surface epithelium which, by definition, is decreased in celiac sprue. The cell type of origin of mucosal folate conjugase has not been defined. The present finding of a dissimilar effect of celiac sprue on whole mucosal folate conjugase and disaccharidase suggests that these enzymes are concentrated in different cell types. Mucosal folate conjugase could predominate in cells infiltrating the lamina propria or in cells of the crypt or surface epithelium. Others have shown negligible folate conjugase in circulating lymphocytes (30), whereas we have demonstrated its activity in isolated mucosal epithelial cells of the rat (32). Although direct experimental evidence is lacking, the finding of increased folate conjugase activity in celiac sprue biopsies suggests that its activity may predominate in the hyperplastic crypt epithelium of this mucosal disease.

\section{ACKNOWLEDGMENTS}

We are indebted to Dr. C. L. Krumdieck, The Nutrition Program, University of Alabama, Birmingham, Ala. and to Dr. C. M. Baugh, University of South Alabama, Mobile, Ala. who supplied the labeled pteroylpolyglutamates used in these studies, and to Dr. C. E. Butterworth, Jr. for continued invaluable critical advice. In addition, we thank Doctors Robert Bolt, Ralph Breitenstein, and James Hansen for referral of several of the patients studied, and Dr. C. J. Rosenquist for assistance in fluoroscope control of intestinal tube placement.

This work was supported by award 465 from The Nutri- tion Foundation, Clinical Investigator award 1-K08-AM70293, and Research grant AM18330-01 from the National Institute of Arthritis, Metabolism, and Digestive Diseases. Folate synthesis was supported by grants AM08644 from the National Institutes of Health and 1C-3M from the American Cancer Society.

\section{REFERENCES}

1. Butterworth, C. E., Jr., R. Santini, Jr., and W. B. Frommeyer, Jr. 1963. The pteroylglutamate components of American diets as determined by chromatographic fractionation. J. Clin. Invest. 42: 1929-1939.

2. Butterworth, C. E., Jr., C. M. Baugh, and C. Krumdieck. 1969. A study of folate absorption and metabolism in man utilizing carbon-14-labeled polyglutamates synthesized by the solid phase method. J. Clin. Invest. 48: $1131-1142$.

3. Baugh, C. M., C. L. Krumdieck, H. J. Baker, and C. E. Butterworth, Jr. 1971. Studies on the absorption and metabolism of folic acid. Folate absorption in the dog after exposure of isolated intestinal segments to synthetic pteroylpolyglutamates of various chain lengths. J. Clin. Invest. 50: 2009-2021.

4. Halsted, C. H., C. M. Baugh, and C. E. Butterworth, Jr. 1975. Jejunal perfusion of simple and conjugated folates in man. Gastroenterology. 68: 261-269.

5. Rosenberg, I. H., R. R. Streiff, H. A. Godwin, and W. B. Castle. 1969. Absorption of polyglutamic foiate: participation of deconjugating enzymes of the intestinal mucosa. N. Engl. J. Med. 280: 985-988.

6. Hoffbrand, A. V., and T. J. Peters. 1970. Recent advances in knowledge of clinical and biochemical aspects of folate. Schweiz. Med. Wochenschr. 100: 1954-1960.

7. Baugh, C. M., J. C. Stevens, and C. L. Krumdieck. 1970. Studies on $\gamma$-glutamyl carboxypeptidase. I. The solid phase synthesis of analogs of polyglutamates of folic acid and their effects on human liver $\gamma$-glutamyl carboxypeptidase. Biochim. Biophys. Acta. 212: 116-125.

8. Herbert, V. 1966. Aseptic addition method for Lactobacillus casei assay of folate activity in human serum. J. Clin. Pathol. (Lond.). 19: 12-16.

9. Van de Kamer, J. H., H. ten Bokkel Hunnik, and H. A. Weyers. 1949. Rapid method for the determination of fat in feces. J. Biol. Chem. 177: 347-355.

10. Roe, J. H., and E. W. Rice. 1948. A photometric method for the determination of free pentoses in animal tissues. J. Biol. Chem. 173: 507-512.

11. Schenk, E. A., and F. A. Klipstein. 1972. A protocol for the evaluation of small bowel biopsies. Am. J. Clin. Nutr. 25: 1108-1117.

12. Krumdieck, C. L., and C. M. Baugh. 1969. The solid phase synthesis of polyglutamates of folic acid. Biochemistry. 8: 1568-1572.

13. Malawer, S. J., and D. W. Powell. 1967. An improved turbidimetric analysis of polyethylene glycol utilizing an emulsifier. Gastroenterology. 53: 250-256.

14. Baugh, C. M., and C. L. Krumdieck. 1971. Naturally occurring folates. Ann. N. Y. Acad. Sci. 186: 7-28.

15. Rabinowitz, N. C. 1960. Folic acid. Enzymes. 7: 185252.

16. Lowry, O. H., N. J. Rosenbrough, A. L. Farr, and R. J. Randall. 1951. Protein measurements with Folin phenol reagent. J. Biol. Chem. 193: 265-275.

17. Krumdieck, C. L., and C. M. Baugh. 1970. Radioactive assay of folic acid polyglutamate conjugase(s). Anal. Biochem. 35: 123-129. 
18. Dahlqvist, A. 1968. Assay of intestinal disaccharidases. Anal. Biochem. 22: 99-107.

19. Whalen, G. E., J. A. Harris, J. E. Geenen, and K. H. Soergel. 1966. Sodium and water absorption from the human small intestine. The accuracy of the perfusion method. Gastroenterology. 51: 975-984.

20. Rosenberg, I. H. 1976. Absorption and malabsorption of folates. Clinics in Haematology. 5: 589-618.

21. Weir, D. G. 1974. The pathogenesis of folic acid deficiency in man. Ir. J. Med. Sci. 143: 3-20.

22. Cooke, W. T., D. G. Fone, E. V. Cox, M. J. Meynell, and R. Gaddie. 1963. Adult coeliac disease. Gut. 4: 279-291.

23. Stewart, J. S., D. J. Pollack, A. V. Hoffbrand, D. L. Mollin, and C. C. Booth. 1967. A study of proximal and distal intestinal structure and absorptive function in idiopathic steatorrhea. Q.J. Med. 36: 425-444.

24. Hoffbrand, A. V., A. P. Douglas, L. Fry, and J. S. Stewart. 1970. Malabsorption of dietary folate (pteroylpolyglutamates) in adult coeliac disease and dermatitis herpetiformis. Br. Med. J. 4: 85-89.

25. Fordtran, J. S., F. C. Rector, T. W. Locklear, and M. F. Ewton. 1967. Water and solute movement in the small intestine of patients with sprue. J. Clin. Invest. 46: 287298.
26. Schmid, W. C., S. F. Phillips, and W. H. J. Summerskill. 1969. Jejunal secretion of electrolytes and water in nontropical sprue. J. Lab. Clin. Med. 73: 772-783.

27. Gerson, C. D., N. Cohen, G. W. Hepner, N. Brown, V. Herbert, and H. D. Janowitz. 1971. Folic acid absorption in man: enhancing effect of glucose. Gastroenterology. 61: 224-227.

28. Gerson, C. D., N. Cohen, N. Brown, J. Lindenbaum, G. W. Hepner, and H. D. Janowitz. 1974. Folic acid and hexose absorption in sprue. Am. J. Dig. Dis. 19: 911-919.

29. Corcino, J. J., A. M. Reisenauer, and C. H. Halsted. 1976. Jejunal perfusion of simple and conjugated folates in tropical sprue. J. Clin. Invest. 58: 298-305.

30. Jägerstad, M., K. Lindstrand, Å., Nordén, A-K. Westesson, and T. Lindberg. 1974. The folate conjugase activity of the intestinal mucosa in celiac disease. Scand. J. Gastroenterol. 9: 255-259.

31. Douglas, A. P., T. J. Peters, A. V. Hoffbrand, and C. C. Booth. 1970. Studies of intestinal peptidases with special reference to coeliac disease. In Coeliac Disease. C. C. Booth, and R. H. Dowling, editors. Churchill Livingstone, Edinburgh and London. 115-123.

32. Halsted, C. H., A. Reisenauer, C. Back, and G. S. Gotterer. 1976. In vitro uptake and metabolism of pteroylpolyglutamate by rat small intestine. J. Nutr. 106: 485-492. 